\title{
Humero-radio-ulnar synostosis
}

INSERM

\section{Source}

INSERM. (1999). Orphanet: an online rare disease and orphan drug data base. Humeroradio-ulnar synostosis. ORPHA:3266

Humero-radio-ulnar synostosis is an extremely rare, genetic, congenital joint formation defect disorder characterized by uni- or bilateral fusion of the humerus, radius and ulnar bones, leading to loss of elbow motion and, in most, functional arm incapacity. It may appear as distal humeral bifurcation with absent elbow joint and shortened arm length on imaging. Hand abnormalities, namely oligoectrosyndactyly, may be associated. 